indicated by a partial anterior rim of hair, there can be no doubt as to its presence.

The signafiranoe of the oongenital frontal band alopooia.The congenital frontal band alopecia often runs in families and is hereditary. In one case an acquired frontal band was added to a pre-existing congenital band. In both children and adults I have found it constantly associated with enlargement of the thyroid and tachycardia, nervousness, pigmenta. tion, chilblains, epistaxis, patchy baldness, and sometimes tremors, a condition that suggests potential Graves's disease. In 18 cases of exophthalmic goitre the congenital frontal band alopecia has been found present, and no negative instance has so far occurred. Out of six cases of myxcedema the frontal band alopecia was found in five, of whom two showed unequivocal and the other three less marked signs and symptoms of exophthalmic goitre. The sixth had no frontal band alopecia and nothing to suggest past or present Graves's disease.

So far some 98 cases of frontal band alopecia have been investigated. The present preliminary note is written with a view of inviting the attention of medical men who may be wiling to help in further investigation of an interesting point. The band may possibly indicate some evolutionary change or may be degenerative or tropho-neurotic, or be a part of the obecure group of signs and symptoms associated with exophthalmic goitre. The age at which the hair grows over the frontal band area in normal cases is under investigation and will be determined by an examination of many hundreds of children out:ide the nospital class.

Bryanston-street, $W$.

-

\section{A CASE OF}

INTRAPARIETAL HERNIA WITH VERY SMALL PERITONEAL OPENING, GIVING RISE TO SEVERE ABDOIINAL PAIN.

\section{BY JOHN A. O. MACEWEN, M.B., B.Sc. GLASG.,} F F.P S. GLASG,

SEMIOR ASSISTANT TO RFGIUS PROFESSOR OF SURGERY ; ASSISTANT SURGEON, GLASGOW ROYAL IYFIRMARY; SIRGEOY TO THE ELDER COTTAGE HOSPITAL, GOVAN.

THE patient, a married woman, aged 57 years, was seen by me in February at the Elder Hospital, Govan, complaining of abdominal pain, particularly at a point about midway between the umbilicus and symphysis and two inches to the right of the middle line. She stated that this pain began to trouble her about two years previously and that it had been gradually getting worse. It was aggravated by work and relieved by lying down and at times it was so severe as to canse sickness and faintness. She had already sought surgical advice but nothing had been detected which would account for the pain.

On examination the abdomen was found to be very pendulous and loaded with fat, rendering accurate palpation very difficult. The recti muscles were much displaced laterally. The patient had a small umbilical hernia which was not tender and gave rise to no discomfort; otherwise nothing could be made out save that over the site of the tender point it was thought that a slight thickening of the abdominal wall could be detected. This thickening however, was indefinite and she was therefore asked to return for further examination at a later date. This she did and on examination while standing a large mass of about the size of the closed fist with a narrow pedicle extending toward the abdominal cavity was detected. The patient now lay down and when an attempt was made to grasp the tumour for the purpose of further examination there were a surden slip and slight gurgle and the swelling disappeared. Up to the time of operation many further attempts were made to get the mass to reappear but without avail, only the feeling of slight thickening in the abdominal wall being discoverable.

Operation.-The small umbilical hernia, which was loculated, was first treated and then the abdominal incision was prolonged downwards in the middle line for about three inches and the inner surface of the abdominal wall was inspected. The finger, passing over the smooth peritoneal surface, detected just at the point previously indicated by the patient as painful a slight thickening, certainly not mor than a quarter of an inch in diameter. The abdominal wall was now everted and close inspection revealed a small raised area with a minute central depression. So small was this depression that it was doubtful if it would admit a probe. Sligbt pressure with the point of the probe, however, served to gain access to what appeared to be a small sac in the abdominal wall. Dressing forceps were next tried and it was found that the minute mouth of the sac was extremely distensible, easily opening sufficiently to admit the finger, which penetrated a distance of one and a half inches when a little pressure was applied. An incision was now made round the mouth of the sac in the normal peritoneum and the sac, which then lay loosely in the abdominul wall, was dissected out. While very small when relaxed and, as already stated, possessing a very narrow mouth, it was capable of great distension, extending easily to the size of a Tangerine orange. A further point of interest was that the omentum, instead of lying in front of the coils of bowel, had become turned up, its free border being attached to the stomach and the whole being laden with fat. An attempt was made to remedy this and a redundant portion was removed. The wounds were now sutured, particular care being taken to secure accurate apposition of the cut peritoneal surfaces, and the patient was returned to bed. She made an uninterrupted recovery and has had no further trouble, the pain having quite disappeared.

The point of chief interest in this case is the extreme variability in the size of the sac which at times was very small, presenting a merely potential opening, while at others it was large and distended with bowel. The pain, on the other hand, while no doubt varying in degree, was constantly present save when the patient lay down, and thus one was faced by the problem of a patient suffering very considerable abdominal pain, particularly at a definite spot, in whom no definite lesion could be made out.

I have known patients suffering from small umbilical hernia state that at an early stage of the affection, before any prominent external tumour had appeared, they frequently had attacks of violent abdominal pain which compelled them to hold the abdomen with the hands while walking. In such cases I think the condition would be very similar to what was found in this one-a sac with a very narrow but distensible mouth. Probably the pain in such cases is due in part to nipping of a portion of the lumen of the bowel in the narrow mouth (causing the sickness and faintness referred to) and in part to the distension of the narrow mouth causing pressure on, and irritation of, the peripheral nerves.

Giasgow.

\section{MULTIPLE FIBRO-MYXOMATA OF THE CHOROID PLEXUS.}

BY MARGARET B. DOBSON, M.D. LOND., PATHOLOGIST TO THE WEST RIDING ASYLUM, WAKEFIELD.

THE patient, a widow, aged 52 years, was admitted into the West Riding Asylum, Wakefield, in August, 1901, suffering from mania of some months' duration; she died in May, 1906, from tuberculosis of the lungs and intestines. Her form of mental disease at death was secondary dementia. Intemperance was the most potent etiological factor.

A necropsy was made $23 \frac{1}{2}$ hours after death. The skull was thick and dense; the dipluë was almost obliterated. A rough deposit of new bone was found on the inner surface of the calvarium in the frontal region. The dura mater was thick and fibrous and firmly adherent to the skull in the frontal region. The Pacchionian bodies were greatly increased in size but not in numbers The subdural space was distended with an excess of normal-looking cerebrospinal fluid. The pia arachnoid was œedematous and gelatinous-looking all over the convexity of the brain, and milky opacities were seen along the course of the large veins. The sub-arachnoid meshes contained an excess of cerebrospinal fluid. The brain weighed 1265 grammes. The hemispheres were symmetrical. The frontal lobes were much atrophied, the gyri being yellow in colour, somewhat ungular and shrivelled, while the intervening sulci were shallow and gaped widely. The cortical surface was smooth and uneroded, and the general consistence of the brain was rednced. The lateral ventricles were both dilated and contained an excess of ctrebro-spinal fluid. The ependymal lining was smooth and glistening; the vein of the corpus striatum was congested and tortuous. The 